\title{
Süstalinable Chemistry\& Engineering \\ Moderate Electric Fields as a Potential Tool for Sustainable Recovery of Phenolic Compounds from Pinus pinaster Bark
}

Pedro Ferreira-Santos, ${ }^{\dagger \oplus}$ Zlatina Genisheva, ${ }^{\dagger} \odot$ Ricardo N. Pereira, ${ }^{\dagger \oplus}$ José A. Teixeira, ${ }^{\dagger \odot}$ and Cristina M. R. Rocha ${ }^{*} \dagger \odot$

${ }^{\dagger} \mathrm{CEB}$ - Centre of Biological Engineering, University of Minho, Campus de Gualtar, 4710-057 Braga, Portugal

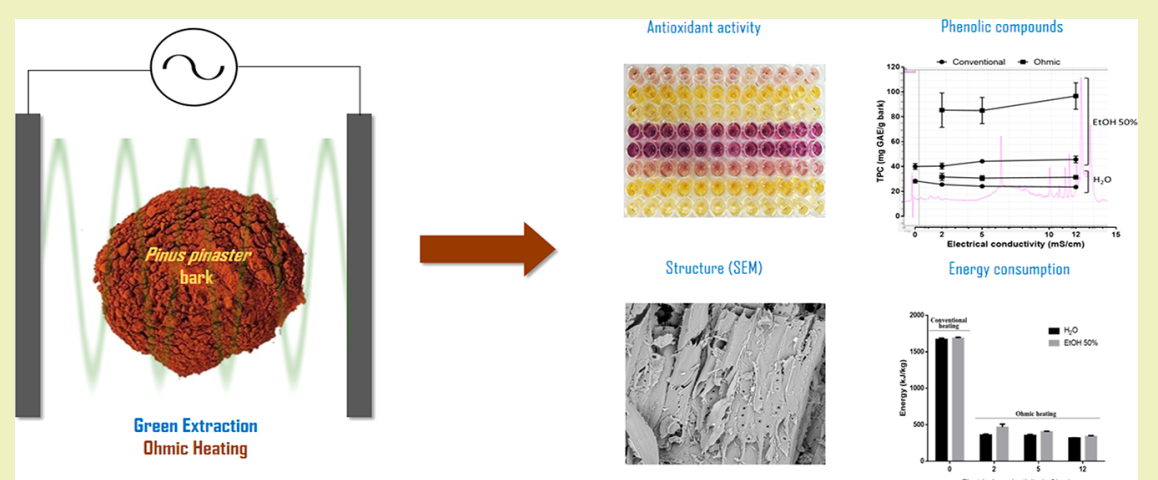

ABSTRACT: Pinus pinaster (pine) bark is a widely available wood industry byproduct but an underexploited source of phenolic compounds with a strong antioxidant activity. The aim of this study was to evaluate the effectiveness of ohmic heating $(\mathrm{OH}$, a recognized eco-friendly, electric fields-based processing technology) for the sustainable recovery of phenolic compounds from Pinus pinaster bark. Results of $\mathrm{OH}$ evidenced increased extraction of antioxidant phenolic compounds with no degradation of pine bark extracts for all tested conditions. Moreover, the enhancement in phenolic content in OH-assisted extraction was particularly evident when using a hydroethanolic solvent with 50\% ethanol, reaching improvements higher than $100 \%$, when comparing to the conventional approach. This fact may indicate preferential extraction, presumably due to the action of electric field effects acting in synergy with heat and solvents. Furthermore, additional changes in the morphological structure of bark cells were observed upon $\mathrm{OH}$-assisted extraction, suggesting membrane electroporation effects. A significant reduction in energy consumption when compared with the conventional process was observed, leading to an energetically more sustainable approach. $\mathrm{OH}$ technology holds the potential to be a "green" alternative, with higher extraction yields and reduced energy consumption and offering the possibility of tuning the selectivity toward phenolic compounds.

KEYWORDS: Pinus pinaster bark, Phenolic compounds, Conventional thermal extraction, Ohmic heating, Cells permeability, Energy consumption, Sustainable extraction

\section{INTRODUCTION}

Pinus pinaster (maritime pine) is considered a plant of the conifer family native to North-Western Africa and some European countries, growing and adapting strongly in the forests of France, Spain, and Portugal. ${ }^{1}$ The Portuguese $P$. pinaster forest reached its highest area in $1995\left(978 \times 10^{3} \mathrm{ha}\right)$ and has been reduced since that time, being $714 \times 10^{3}$ ha in 2010. However, this species represents an important part of the total forest (about of 23\%), being the third most important species after eucalyptus $(812 \times 103$ ha, $26 \%)$ and cork oak $(737 \times 103 \text { ha, } 23 \%)^{2}$

Pine bark (PB) is a byproduct of the wood industry (sawmills, wood panels, pulp and paper, carpentry, packaging, and furniture) representing 10 to $20 \%$ of the total pine trunk composition. This waste is usually used for energy production or simply discarded, being only a very low percentage used for high value and industrial applications (pharmaceutical and supplement nutrition, polymers formation and biobased materials, biopesticides, etc.). ${ }^{3}$ However, this lignocellulosic waste has several profitable characteristics, such as low price, long-term stability, and important phytochemical constituents, which together make the use of this residue highly attractive for investigations aimed at improving the value of such material. ${ }^{4}$ The transformation of this waste in high added value products is important for the economy of countries where this species grows abundantly.

Presently, the exclusive commercial product of $P$. pinaster bark (pycnogenol), obtained by the application of conventional heating using water as solvent is an example of the use of this material to generate products of high industrial interest. ${ }^{5}$ The extracts of $\mathrm{PB}$ are highly rich in numerous phenolic compounds such as catechin, taxifolin, procyanidins, and

Received: February 7, 2019

Revised: $\quad$ March 19, 2019

Published: March 26, 2019 
Table 1. Electrical Conductivity and $\mathrm{pH}$ of Solvents and Extracts ${ }^{a}$

\begin{tabular}{|c|c|c|c|c|c|c|c|}
\hline & \multirow[b]{3}{*}{$\begin{array}{l}\text { concentration } \mathrm{NaCl} \\
\text { (M) }\end{array}$} & & & \multicolumn{4}{|c|}{ extacts } \\
\hline & & \multicolumn{2}{|c|}{ solvent } & \multicolumn{2}{|c|}{ conventional } & \multicolumn{2}{|c|}{ ohmic } \\
\hline & & $\begin{array}{l}\text { conductivity } \\
(\mathrm{mS} / \mathrm{cm})\end{array}$ & $\mathrm{pH}$ & $\begin{array}{l}\text { conductivity } \\
(\mathrm{mS} / \mathrm{cm})\end{array}$ & $\mathrm{pH}$ & $\begin{array}{l}\text { conductivity } \\
(\mathrm{mS} / \mathrm{cm})\end{array}$ & $\mathrm{pH}$ \\
\hline \multirow[t]{4}{*}{$\mathrm{H}_{2} \mathrm{O}$} & 0.00 & $0.02 \pm 0.00$ & $5.79 \pm 0.13$ & $0.32 \pm 0.01$ & $4.51 \pm 0.04$ & & \\
\hline & 0.02 & $2.04 \pm 0.15$ & $5.63 \pm 0.12$ & $2.29 \pm 0.04$ & $4.22 \pm 0.05$ & $2.33 \pm 0.00$ & $4.20 \pm 0.01$ \\
\hline & 0.05 & $4.95 \pm 0.00$ & $5.61 \pm 0.05$ & $5.50 \pm 0.01$ & $4.03 \pm 0.01$ & $5.62 \pm 0.00$ & $4.03 \pm 0.02$ \\
\hline & 0.15 & $12.05 \pm 0.08$ & $5.68 \pm 0.00$ & $12.65 \pm 0.13$ & $3.86 \pm 0.00$ & $12.53 \pm 0.23$ & $3.81 \pm 0.01$ \\
\hline \multirow[t]{4}{*}{ EtOH $50 \%$} & 0.00 & $0.00 \pm 0.00$ & $6.10 \pm 0.14$ & $0.08 \pm 0.01$ & $4.76 \pm 0.02$ & & \\
\hline & 0.04 & $2.01 \pm 0.00$ & $5.76 \pm 0.38$ & $2.32 \pm 0.02$ & $4.18 \pm 0.05$ & $2.44 \pm 0.09$ & $4.06 \pm 0.03$ \\
\hline & 0.18 & $4.94 \pm 0.06$ & $5.57 \pm 0.24$ & $5.98 \pm 0.011$ & $3.98 \pm 0.01$ & $5.99 \pm 0.04$ & $3.93 \pm 0.01$ \\
\hline & 0.50 & $12.16 \pm 0.01$ & $5.75 \pm 0.07$ & $14.47 \pm 0.04$ & $3.77 \pm 0.03$ & $14.42 \pm 0.44$ & $3.68 \pm 0.04$ \\
\hline
\end{tabular}

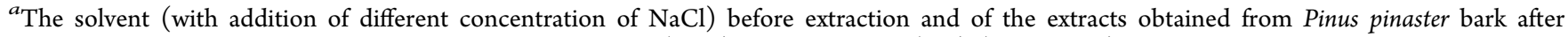
conventional or $\mathrm{OH}$-assisted extraction methods using water $\left(\mathrm{H}_{2} \mathrm{O}\right)$ or ethanol $50 \%(\mathrm{v} / \mathrm{v})(\mathrm{EtOH} 50 \%)$ as solvents. Values are expressed as mean $\pm \mathrm{SD}$ of 3 experiments.

phenolic acids. These extracts have been shown to exhibit different modes of action, including antiradical, antioxidant, anti-inflammatory, and antiviral properties, and some applications of such extracts are described in the literature. ${ }^{5-9}$

Traditional extraction techniques (such as maceration and Soxhlet) used to recover polyphenolic compounds from different plant-based matrices are time-consuming and often require high solvent and energy consumptions, thus generating large amounts of waste. ${ }^{10,11}$ In recent years, greater consciousness of environmental issues has allowed a growing movement toward the use of so-called "green" technologies. An example of this paradigm shift is related to the growing demand for cleaner extraction techniques, such as microwave-assisted extraction, high pressure extraction, and ultrasound-assisted extraction, for the recovery of bioactive compounds. ${ }^{12-14}$ These new green processes are meant to be more environmentally friendly with shorter extraction times and lesser consumption of organic solvents and energy, while maintaining a high quality of extracts. ${ }^{12,15-17}$

Recently, electrotechnologies such as pulsed electric fields (PEF), high voltage electrical discharges (HVED), and ohmic heating $(\mathrm{OH})$ have been also applied to the extraction of molecules of interest from plant materials. ${ }^{11,18} \mathrm{OH}$ is a promising technology, as a process in which heating occurs by the transformation of internal energy from electrical to thermal, ${ }^{11,19}$ leading to almost instantaneously and uniform heating. $\mathrm{OH}$ can further induce not only thermal but also the electro-permeabilization of the cell membranes, and this phenomenon was assumed to be relevant in the experiments conducted on extraction of essential oils and bioactive molecules from different bioresources. ${ }^{1,18-20}$

In this context, this study was designed to evaluate the aptness of $\mathrm{OH}$-assisted extraction combined with water or water/ethanol mixture as solvent to obtain extracts with high content of phenolic compounds from $P$. pinaster bark. Moreover, studies were made in order to access possible chemical differences of the extracts, as well as morphological changes of the bark cells. Results of $\mathrm{OH}$-assisted extraction were also compared with a conventional heating performed under identical conditions. Effects of electrical conductivity and electric field were also addressed to a better understanding of the nonthermal effects of the $\mathrm{OH}$ in the extraction process.

The final aim was to achieve a feasible, low-cost, and lowenvironmental impact extraction process. As far as we know, this is the first time that ohmic heating-assisted extraction has been used to extract phenols from lignocellulosic residues, and its effects on the process yield, selectivity, and energetic efficiency are evaluated.

\section{EXPERIMENTAL SECTION}

Raw Material. Pine bark (from P. pinaster) was collected in the North region of Portugal (Ponte de Lima, Viana do Castelo, Portugal) in April 2016. The trees had an approximate age between 29 and 32 years. First, the bark was washed with distilled water several times to remove dirt, lichens, and resin. The bark was dried at $40{ }^{\circ} \mathrm{C}$ for $48 \mathrm{~h}$ and subsequently milled in a cutting mill (Retsch Mill MM 2000, Retsch, Haan, Germany) to a granulometry of $1-1.6 \mathrm{~mm}$. Finally, the ground $\mathrm{PB}$ was kept in a sealed bags and stored in a dry and dark place until further analysis.

$\mathrm{OH}$ Equipment. Extractions were performed in a cylindrical glass reactor, double-walled water-jacketed $(3 \mathrm{~mm}$ of internal diameter and $100 \mathrm{~mm}$ height) with two inox electrodes. The design of reactor was described elsewhere. ${ }^{21}$ The distance between electrodes was kept constant $(3.2 \mathrm{~cm})$. The power source working with a sinusoidal wave at $25 \mathrm{kHz}$ (Agilent 33220A, $1 \mathrm{~Hz}-25 \mathrm{MHz}$ and $1-10 \mathrm{~V}$; Penang, Malaysia) allowed changing the voltage. Temperature was recorded with a type-K thermocouple (temperature precision of $\pm 1{ }^{\circ} \mathrm{C}$; Omega Engineering, Inc., Stamford, CT, U.S.A.), located in the geometric center of the extractor's volume. The thermocouple was connected to a data logger (USB-9161, National Instruments Corporation, Austin, TX, U.S.A.), and Lab View 7 Express software (National Instruments, NI Data logger) was used to extract the data. A portable oscilloscope (ScopeMeter 125/S, Fluke, WA, U.S.A.) was used to measure electrical frequency, voltage, and current intensity during $\mathrm{OH}$ treatments.

The reactor was covered properly to avoid the loss of solvent and the direct incidence of light.

Conventional and $\mathrm{OH}$ Heating Extraction Conditions. For extractions, $1.5 \mathrm{~g}$ of dried $\mathrm{PB}$ was mixed with $15 \mathrm{~mL}$ of solvent (water or ethanol $50 \%$ ) in a reactor (described above) with a magnetic stirrer (size of $0.5 \mathrm{~cm}$ ) at $150 \mathrm{rpm}$, introduced inside the reactor vessel to homogenize the solution and improve heat transfer during the heating cycle. For the conventional thermal treatment $(0 \mathrm{~V} / \mathrm{cm})$, a thermostatic circulator water system (F25-ED, Julabo, Seelbach, Germany) was used to get the same heating rates in all types of treatments. Sodium chloride $(\mathrm{NaCl})$ was selected as a conducting medium due to higher electrical conductivity and prepared to ensure a homogeneous current flow and poured to the processing chamber in a solid-liquid ratio. ${ }^{22}$ Experiments were carried out using different concentrations of $\mathrm{NaCl}$ in the extraction medium (i.e from 0 to 0.5 M) that allowed the values of electrical conductivity to be maintained comparable between the different types of solvent used in the extraction (water and ethanol), as well as to change for each solvent the electric field intensity applied (see Table 1 ). The extractions were 
made in triplicate and kept at $83 \pm 1{ }^{\circ} \mathrm{C}$ for $30 \mathrm{~min}$ (conditions chosen from preliminary study, data not shown).

Total Extractives. Total extractives were determined in accordance to National Renewable Energy Laboratory (NREL) procedure. $^{23}$ For the exhaustive extraction were used $2 \mathrm{~g}$ of $\mathrm{PB}$ in $100 \mathrm{~mL}$ of ethanol $96 \%(\mathrm{v} / \mathrm{v})$ during $21 \mathrm{~h}$ at $100{ }^{\circ} \mathrm{C}$ in an automatic Soxhlet extraction system (Soxtec 8000, FOSS, Denmark).

Conductivity and $\mathrm{pH}$. The $\mathrm{pH}$ of the solutions and extracts was measured using a $\mathrm{pH}$ meter (HANNA Instruments Inc., HI2210, U.S.A.), and the conductivity was measured using a conductivity/ TDS/Salinity Meter (HANNA Instruments Inc., edge, HI2003, USA) at $21 \pm 1{ }^{\circ} \mathrm{C}$.

Extraction Yield. The solvent efficiency in extracting target compounds from a dry material can be measured using the extraction yield. Yield calculation (presented in \%) was made using eq 1 , considering cumulative mass of extract:

$$
\text { yield }=\frac{\text { extracted solids }(\mathrm{g})}{\text { initial dry material }(\mathrm{g})} \times 100
$$

Total Phenolic Compounds Determination. The concentration of total phenolic compounds (TPC) was measured using the Folin-Ciocalteu method, which is based on the colorimetric reduction/oxidation reaction of phenols. ${ }^{24}$ For all analyses, $5 \mu \mathrm{L}$ of extract (water or ethanol $50 \%$ for control) was mixed with $60 \mu \mathrm{L}$ Folin-Ciocalteu reagent, $15 \mu \mathrm{L}$ of $\mathrm{Na}_{2} \mathrm{CO}_{3}(75 \mathrm{~g} / \mathrm{L})$. The prepared solution was kept at $60{ }^{\circ} \mathrm{C}$ for $5 \mathrm{~min}$. Absorbance was measured at $700 \mathrm{~nm}$ by an UV/vis spectrophotometer (Synergy HT, BioTek Instruments, Inc., U.S.A.). A calibration curve was prepared using a standard solution of gallic acid. Final values were expressed as milligram gallic acid equivalents (GAE) per gram of dry material ( $\mathrm{mg}$ GAE/g PB).

Determination of Antioxidant Activity. Three different methods of measuring the antioxidant activity was used: DPPH, ABTS, and FRAP. The 2,2-diphenyl-1-picrylhydrazyl radical scavenging activity (DPPH assay) of extracts from $\mathrm{PB}$ was determined as described by Ballesteros et al. ${ }^{25}$ with some modifications. Four different dilutions of each sample were prepared considering that the percent inhibition had to be between $20 \%$ and $80 \%$. The control solution consisted in using solvent of extraction instead of the sample. A calibration curve was prepared with a standard solution of Trolox (6-hydroxy-2,5,7,8-tetramethylchroman-2-carboxylic acid). The radical scavenging activity was calculated by using eq 2 , where Ac and As are the absorbance of the control solution and the absorbance of the sample solution, respectively (measured at $515 \mathrm{~nm}$ ). DDPH percent inhibition data were plotted as a function of antioxidant concentration to obtain DPPH inhibition concentration at 50\% (IC50). The IC50 values were expressed as micromoles of Trolox equivalent (TE) per $\mathrm{g}$ of dry material ( $\mu \mathrm{mol} \mathrm{TE} / \mathrm{g} \mathrm{PB})$.

$$
\text { \%inhibition }=\left[1-\frac{\mathrm{As}}{\mathrm{Ac}}\right] \times 100
$$

The radical cation decolorization (ABTS assay) of extracts was determined as described by Ballesteros et al. $^{25}$ using the ABTS reagent (2,2'-azino-bis(3-ethylbenzothiazoline-6-sulfonic acid) diammonium salt). Each sample was diluted as previously mentioned for the DPPH assay, and the absorbance was measured at $734 \mathrm{~nm}$. Solvent of extraction was used as control solution instead of the sample. A standard solution of Trolox was used to build the calibration curve. The same equation employed in the DPPH radical scavenging was used to calculate the percent inhibition of ABTS radical cation. The IC50 values were expressed as micromoles of TE per gram of dry material $(\mu \mathrm{mol} \mathrm{TE} / \mathrm{g} \mathrm{PB})$. Ferric reducing antioxidant power (FRAP assay) was based on the method described by Benzie and train $^{26}$ and modified by Meneses et al. ${ }^{27}$ The absorbance is determined at $593 \mathrm{~nm}$. An aqueous solution of ferrous sulfate was used to build the calibration curve. FRAP values are expressed as micromoles of ferrous equivalent per $\mathrm{g}$ of dry weight material $(\mu \mathrm{mol}$ $\left.\mathrm{Fe}^{2+} / \mathrm{g} \mathrm{PB}\right)$.
Identification and Quantification of Phenolic Compounds by UPLC-DAD. Samples were analyzed by Shimatzu $N$ expera X2 UPLC chromatograph equipped with Diode Array Detector (DAD) (Shimadzu, SPD-M20A). Separation was performed on a reversedphase Aquity UPLC BEH C18 column $(2.1 \mathrm{~mm} \times 100 \mathrm{~mm}, 1.7 \mu \mathrm{m}$ particle size; from Waters) and a precolumn of the same material at $40{ }^{\circ} \mathrm{C}$. The flow rate was $0.4 \mathrm{~mL} / \mathrm{min}$. HPLC grade solvents water/ formic acid $0.1 \%$ (A) and acetonitrile (B) were used. The elution gradient for solvent B was as follows: from 0.0 to 5.5 min eluent $B$ at $5 \%$, from 5.5 to $17 \mathrm{~min}$ linearly increasing from 5 to $60 \%$, from 17.0 to 18.5 min a linearly increasing from 60 to $100 \%$; last, the column is equilibrated at $5 \%$ from 18.5 to $30.0 \mathrm{~min}$. A comparison between the UV spectra (at different wavelengths) and the retention times of each standard was used to identify and quantify the phenolic compounds. All analyses were made in triplicate.

Morphological Characterization of Bark. The PB, treated and untreated forms, was characterized using a desktop scanning electron microscope (SEM; SEM-Phenom ProX, Phenom-World BV, Netherlands), applying an acceleration voltage of $15 \mathrm{kV}$, at 550 fold magnifications. All SEM pictures were acquired using the ProSuite software (Phenom-World BV, Netherlands).

The samples were added to aluminum pin stubs with electrically conductive carbon adhesive tape (PELCO Tabs). Samples were imaged without coating. The aluminum pin stub was then placed inside a Phenom Charge Reduction Sample Holder (CHR).

Determination of Energy Consumption. The electrical energy consumption of the conventional and $\mathrm{OH}$ treatments was calculated taking into account the data of voltage $(V)$ and current intensity $(A)$ applied during the treatment time and expressed in kW.h.

Statistical Analysis. The extraction and analyses were performed in triplicate and the data are presented as mean \pm standard deviation (SD) values. GraphPad Prism software (version 6.0; GraphPad Software, Inc., San Diego, CA, U.S.A.) was used for statistical analyses. The analysis of variance (ANOVA) and the least significant difference test were used to determine statistically different values at a significance level of $P<0.05$. Principal component analysis (PCA) was used on phenolic compounds to discriminate between extracts. PCA was made using the software XLStat-Pro (Addinsoft, Paris, France, 2011).

\section{RESULTS AND DISCUSSION}

pH and Electrical Conductivity. All results on $\mathrm{pH}$ and electrical conductivity obtained for the solvent before extraction and the extracts of $P$. pinaster bark after complete extraction using different conditions are summarized in Table 1. The results presented show that the electrical conductivity of the solvent is modified using a different concentration of $\mathrm{NaCl}$, as intended, while $\mathrm{pH}$ does not show much variation. After the aqueous and ethanolic extraction the medium containing the extractives show an increase of electrical conductivity $(P<$ $0.05)$, especially in hydroethanolic extracts when higher concentrations of $\mathrm{NaCl}(0.18$ and $0.50 \mathrm{M})$ were used. This increase of electrical conductivity noticed after extraction of the compounds from $P$. pinaster bark can be explained by the leakage of intracellular and extracellular minerals and other conductive compounds from the material to the extraction medium. ${ }^{5}$ This fact was also observed when electrical technologies (such as PEF́s) were applied to different sources, such as foods, plants, etc. ${ }^{28}$ The $\mathrm{pH}$ of extractives is lower than that of the solvent used for their extraction, and it was observed a tendency of $\mathrm{pH}$ decrease when increasing conductivity of the medium confirming the extraction of compounds of acid origin, such as phenolic acids from $P$. pinaster bark. These results may be explained by an ion exchange reaction between the phenolic compounds and $\mathrm{Na}^{+}$. Sodium cation is exchanged against a $\mathrm{H}^{+}$of carboxyl group. This reaction forms a water molecule and phenolic ion, which 
is more soluble in polar solvents (such as water and ethanol) than the initial form of the polyphenol. ${ }^{29}$ No significant differences were detected between the conventional and the $\mathrm{OH}$-assisted extractions in terms of final conductivities and $\mathrm{pH}$.

Extraction Yields. The influence of solvent and electrical conductivity on the extraction yield for the $\mathrm{OH}$-assisted and conventional extraction techniques is shown in Figure 1. The

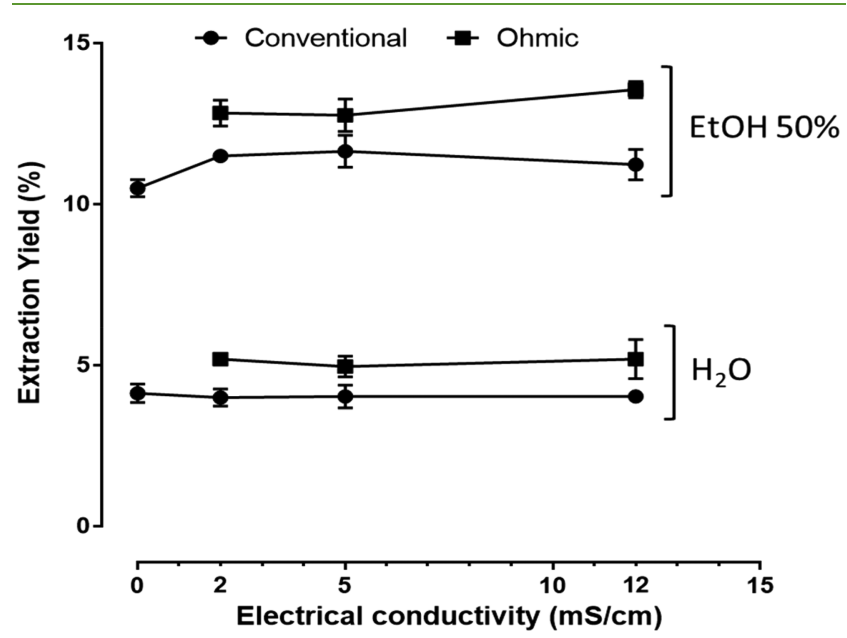

Figure 1. Extraction yields (\%), influence of solvent, and electrical conductivity using conventional heating and $\mathrm{OH}$-assisted extraction methods in Pinus pinaster bark. Values are expressed as mean \pm SD of three experiments.

total amount of extractible material, and thus the maximum possible yield value of extractive compounds, was determined after exhaustive Soxhlet extraction (ethanol 96\% (v/v), 24h at $83{ }^{\circ} \mathrm{C}$ ), representing $13.2 \%$ of total PB composition.

For this byproduct, the results clearly indicate that the extraction yields were significantly increased $(P<0.05)$ when the extraction is performed with ethanol $50 \%(\mathrm{v} / \mathrm{v})$ compared to the aqueous extraction for both methods of extraction (conventional and ohmic heating), which was expected. It is known that most phenolic compounds have higher affinity toward ethanol than water. When extraction is performed with mixtures of organic solvents (such as ethanol or methanol) and water the process is usually more cost-effective in recovering these compounds. The results achieved for the conventional heating treatment with no salt are similar to those referred to in the literature. For instance, Fradinho and co-workers ${ }^{4}$ report that the extractives yield of $P$. pinaster bark was of $10.3 \%$ for ethanol extractives and $3.2 \%$ for water extractives obtained by Soxhlet extraction. In another study using supercritical $\mathrm{CO}_{2}$ extraction or high pressure $\mathrm{CO}_{2}$ and ethanol mixtures (ethanol content ranging from $30 \%$ to $70 \%(\mathrm{v} / \mathrm{v})$ ), the extraction yield was of approximately $4.0 \%$, results much lower than that obtained in this work for ethanolic extracts. ${ }^{1}$ A recent study using microwave assisted extraction and different conditions for extraction of pine bark compounds reports extraction yields of approximately $9.24 \% .{ }^{30}$ Besides the extraction methods, these differences are probably also due to a number of other factors, such as pine bark age, growing conditions, or extraction conditions. Nevertheless, none of the applied reported unconventional methods (high pressure $\mathrm{CO}_{2}$ or microwave), though efficient, seems to have significantly improved extraction yields.
Our results also indicate that the $\mathrm{OH}$-assisted extraction provides a yield very closed to the maximum possible yield using moderate extraction conditions (ethanol $50 \%(\mathrm{v} / \mathrm{v}), 30$ min at $83{ }^{\circ} \mathrm{C}$ ), being able to extract almost $100 \%$ of the extractable material. When comparing $\mathrm{OH}$-assisted extraction with conventional heating, it can be observed that in both studied solvents the extraction yield was significantly higher $(P$ $<0.05)$ in the $\mathrm{OH}$ extraction independently of the tested electrical conductivity. The maximum increase of extraction yield was $17 \%$ in aqueous extraction and $30 \%$ in hydroethanolic extraction when compared to conventional heating. This increase in the extraction yield may be related with the cell wall integrity, which could be weakened by the simultaneous effect of internal temperature increase (Joule effect) and permeation due to electric fields, resulting in a higher contact of the solvent and sample. ${ }^{31}$

Total Phenolic Content. The total phenolic content (TPC) from $P$. pinaster bark at different conditions of extraction is presented in Figure 2. The trends observed are

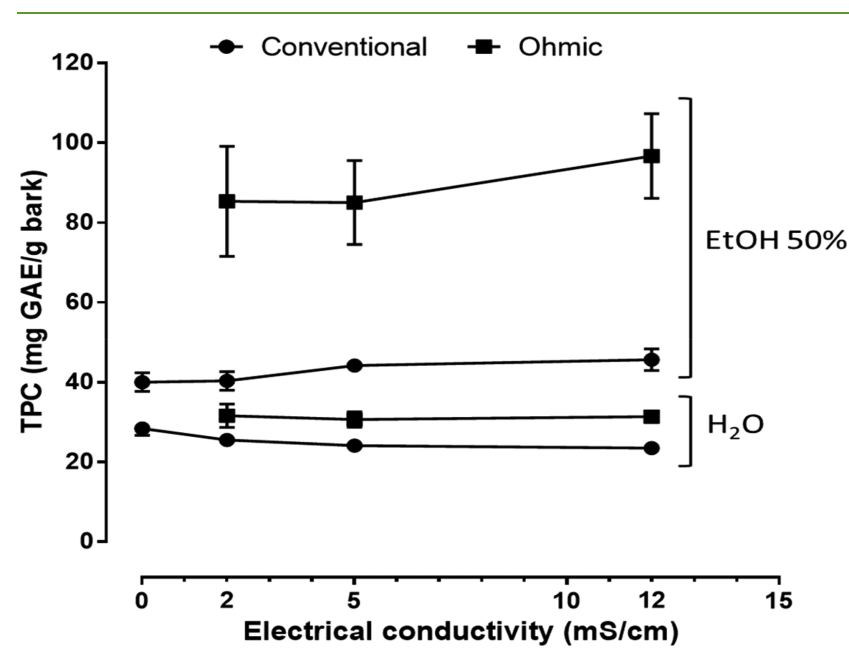

Figure 2. Total phenolic content (TPC) from Pinus pinaster bark. Influence of solvent and electrical conductivity using conventional heating and $\mathrm{OH}$-assisted extraction methods. Values are expressed as mean \pm SD of three experiments; GAE: gallic acid equivalents.

similar to those obtained for the extraction yield. The highest amounts of total phenols are achieved using 50\% ethanolic solution, presenting significantly higher amounts $(P<0.05)$ than with water for both techniques studied and without significant influence of electrical conductivity. It is proved that an increase in the concentration of ethanol accelerated the mass transfer between solvent medium and material and improved the solubility of the polar phenolic compounds. The findings obtained from our study are in agreement with previous studies, which reported that adding water to the alcohol shows synergistic effect, increasing in the extraction yield of phenolic compounds from plant material. ${ }^{1}$ This phenomenon can be explained by the action and properties of the solvents used in the process. Water causes structural changes in the sample, acting as a swelling agent, facilitating the process of transferring solvent into the bark and compounds from the bark to the extraction medium. In addition, the solvent inside the bark causes the disruption of bonds between the solutes and the sample. ${ }^{13,32}$ Furthermore, the high dielectric constant of water is a very important parameter in the extraction process particularly in specific 
Table 2. Antioxidant Activity of the Extracts Obtained from Pinus pinaster bark Measured by Different Methods (FRAP, DPPH, and ABTS $)^{a}$

\begin{tabular}{|c|c|c|c|c|c|c|c|}
\hline & \multirow{2}{*}{$\begin{array}{l}\text { electrical } \\
\text { conductivity } \\
(\mathrm{mS} / \mathrm{cm})\end{array}$} & \multicolumn{2}{|c|}{$\operatorname{FRAP}\left(\mu \mathrm{mol} \mathrm{Fe} e^{2+} / \mathrm{g} \mathrm{PB}\right)$} & \multicolumn{2}{|c|}{$\mathrm{DPPH}(\mu \mathrm{mol} \mathrm{TE} / \mathrm{g} \mathrm{PB})$} & \multicolumn{2}{|c|}{ ABTS $(\mu \mathrm{mol} \mathrm{TE} / \mathrm{g} \mathrm{PB})$} \\
\hline & & conventional & ohmic & conventional & ohmic & conventional & ohmic \\
\hline \multirow[t]{4}{*}{$\mathrm{H}_{2} \mathrm{O}$} & 0 & $531.52 \pm 12.94$ & & $163.84 \pm 1.32$ & & $118.41 \pm 2.43$ & \\
\hline & 2 & $484.76 \pm 9.19$ & $603.19 \pm 61.34$ & $119.48 \pm 7.12$ & $199.14 \pm 6.54$ & $120.01 \pm 11.66$ & $155.88 \pm 28.10$ \\
\hline & 5 & $497.54 \pm 7.75$ & $611.70 \pm 25.97$ & $144.11 \pm 21.20$ & $196.40 \pm 8.25$ & $119.65 \pm 5.25$ & $136.86 \pm 4.73$ \\
\hline & 12 & $473.93 \pm 8.74$ & $559.57 \pm 14.86$ & $113.29 \pm 2.15$ & $195.00 \pm 16.50$ & $110.60 \pm 5.31$ & $139.90 \pm 11.45$ \\
\hline \multirow[t]{4}{*}{ EtOH $50 \%$} & 0 & $1178.78 \pm 70.38$ & & $195.14 \pm 41.53$ & & $425.21 \pm 4.69$ & \\
\hline & 2 & $1320.07 \pm 20.57$ & $2011.56 \pm 191.36$ & $175.17 \pm 7.69$ & $214.94 \pm 15.80$ & $444.44 \pm 45.79$ & $918.49 \pm 36.13$ \\
\hline & 5 & $1248.78 \pm 124.55$ & $2158.59 \pm 236.95$ & $165.09 \pm 7.22$ & $237.27 \pm 38.99$ & $394.28 \pm 23.58$ & $807.73 \pm 115.40$ \\
\hline & 12 & $1286.55 \pm 96.17$ & $2047.48 \pm 279.18$ & $165.07 \pm 6.77$ & $235.45 \pm 26.55$ & $443.40 \pm 20.40$ & $989.75 \pm 94.49$ \\
\hline
\end{tabular}

${ }^{a}$ Values of phenolic compounds are expressed as mean \pm SD of 3 experiments. The extracts were obtained at different electrical conductivities using two extraction methods (conventional and ohmic heating) and with two solvents: water (H2O) or ethanol $50 \%$ (EtOH $50 \%$ ).

extraction technologies such a microwave, ultrasound, and also $\mathrm{OH}^{31}$

A recent investigation using microwave technology and ethanol $80 \%(\mathrm{v} / \mathrm{v})$ as solvent yielded $28.3 \mathrm{mg} \mathrm{GAE} / \mathrm{g}$ bark of phenolic compounds. ${ }^{30}$ This result is comparable to the phenolic content obtained in the present work by the extraction with water for $30 \mathrm{~min}$ at $83{ }^{\circ} \mathrm{C}$ and are in agreement with the results obtained for the total extraction yield.

In the case of TPC, our results demonstrate that $\mathrm{OH}$ is markedly more efficient in extracting phenolic compounds when compared to conventional heating. This is more obvious for hydroethanolic extracts where $\mathrm{OH}$ allowed to almost double the TPC $(P<0.001)$ in comparison with the TPC achieved with the conventional thermal extraction (89.00 and $42.55 \mathrm{mg}$ GAE$/ \mathrm{g}$ bark, respectively). This increase in the extraction of phenolics from pine bark using $\mathrm{OH}$ technology is also observed using water as solvent (31.21 mg GAE/g bark), compared to the conventional extraction technique, $25.38 \mathrm{mg}$ GAE/g bark $(P<0.05)$, though the differences are not so pronounced. This improvement of extraction with $\mathrm{OH}$ treatment is usually ascribed to an electropermeabilization mechanism which facilitates intracellular compounds extraction. ${ }^{11,19,20,33}$ However, differences in the solvent nature seem to have a major role in the $\mathrm{OH}$-based extraction efficiency. In fact, though the improvement in extraction yield caused by $\mathrm{OH}$ is proportionally similar when water or $50 \%$ ethanol are used, differences in total phenolic content are much higher for hydroethanolic extracts, showing that the ohmic heating process is much more selective toward phenolic compounds when the mixture water/ethanol is used. This different extraction behavior may be due to changes in the solvent properties (e.g., in the dielectric constant) caused by the presence of the electric field. In fact, the electric field maybe causing a screening effect of the available charges, leading to higher affinity between the solvent and phenolic compounds and thus increasing their preferential extraction.

Antioxidant Activity. The antioxidant activities of all extracts were evaluated, and results are shown in Table 2.

Antioxidants are known to be beneficial for human health by diminishing the oxidative stress of the body. In general, the bioactive properties (as antioxidant) of the natural resources, in our case of pine bark, may differ from plant to plant due to a number of environmental factors such as the level of maturity, the growing conditions (location, soil status, climate, and agricultural practices), and also the conditions of storage of postharvest material (temperature, time, humidity, presence of contaminants, etc.). ${ }^{34}$

The different methods used for determination of antioxidant activity allows different mechanisms of action of extracts to be evaluated. The FRAP method is based on the reduction of a $\mathrm{Fe}^{3+}$ complex to $\mathrm{Fe}^{2+}$, confirming the presence of reducing antioxidants. DPPH is the simplest and most widely used method for determining the free radical scavenging capacity. The ABTS assay is based on interaction between the antioxidant and ABTS cation radical $\left(\mathrm{ABTS}^{\bullet+}\right)$, that, in the presence of hydrogen donating antioxidant, the $\mathrm{ABTS}^{\bullet+}$ nitrogen atom quenches the hydrogen atom, causing the solution decolorization. This is a stable method and applicable to hydrophilic and lipophilic antioxidant compounds. ${ }^{35,36}$

In the current work and in all of the methods of antioxidant activities studied, the results of antioxidant activity were always higher in the hydroethanolic extracts comparing with aqueous extracts $(P<0.05)$, as expected both from literature and from the yield and total phenolic content results. Moreover, antioxidant activities of extracts made with $\mathrm{OH}$ method, independently of the solvent used, were always higher than the extracts obtained by conventional extraction. Extracts made with the same solvent and method, but with different electrical conductivity had similar antioxidant values. Albeit this may be a critical parameter in $\mathrm{OH}$ processes, as it will dictate the rate of heating, it has no relevant influence on the final extraction yields nor does it alter the quality of the extracts, at least in the case of pine bark extracts in the experimental range tested. Extractives made with ethanol 50\% (v/v) using $\mathrm{OH}$ had the highest antioxidant activities, and showed antioxidant activities that in some cases were almost double of those of extracts obtained with the conventional method $(P<0.01)$. For example, for extracts made with $50 \%$ ethanol and electrical conductivity of $5 \mathrm{mS} / \mathrm{cm}$, the antioxidant activities of the conventional and $\mathrm{OH}$ methods using FRAP were 1248.78 $\mu \mathrm{mol} \mathrm{Fe} e^{2+} / \mathrm{g} \mathrm{PB}$ and $2158.59 \mu \mathrm{mol} \mathrm{Fe} \mathrm{F}^{2+} / \mathrm{g} \mathrm{PB}$, respectively; for the DPPH method the measured activity was $165.09 \mu \mathrm{mol}$ TE/g PB and $237.27 \mu \mathrm{mol} \mathrm{TE} / \mathrm{g} \mathrm{PB}$, respectively; and for the ABTS method the antioxidant values were $394.28 \mu \mathrm{mol} \mathrm{TE} / \mathrm{g}$ $\mathrm{PB}$ and $807.73 \mu \mathrm{mol} \mathrm{TE} / \mathrm{g} \mathrm{PB}$, respectively. As mentioned previously the increase of the antioxidant activity is more visible when $\mathrm{OH}$ and hydroethanolic solvents are used. Increased activity determined by DPPH was more pronounced in the aqueous extracts (up to $72 \%$ ), compared with FRAP and 


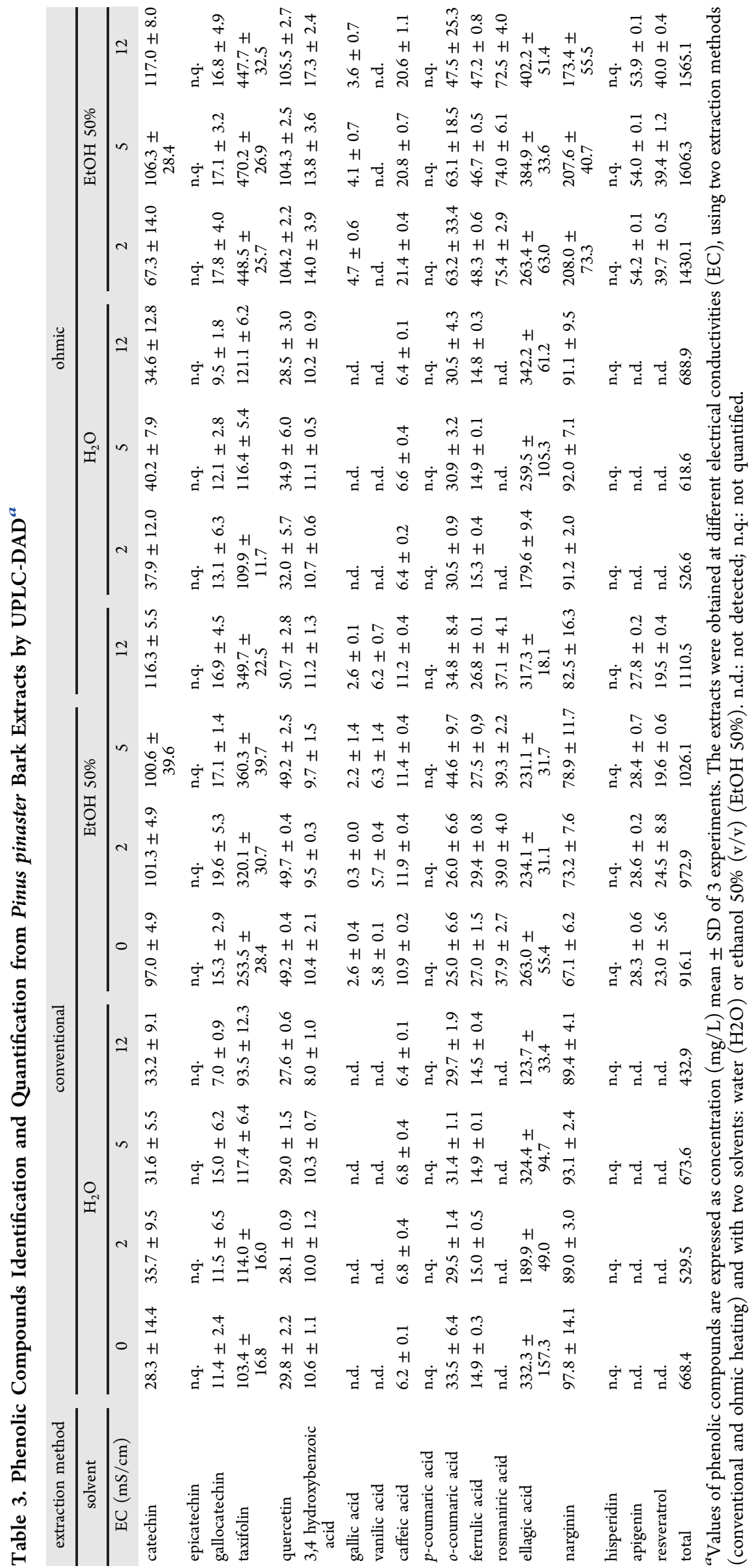


Biplot (axes PC1 and PC2: $81.33 \%$ )

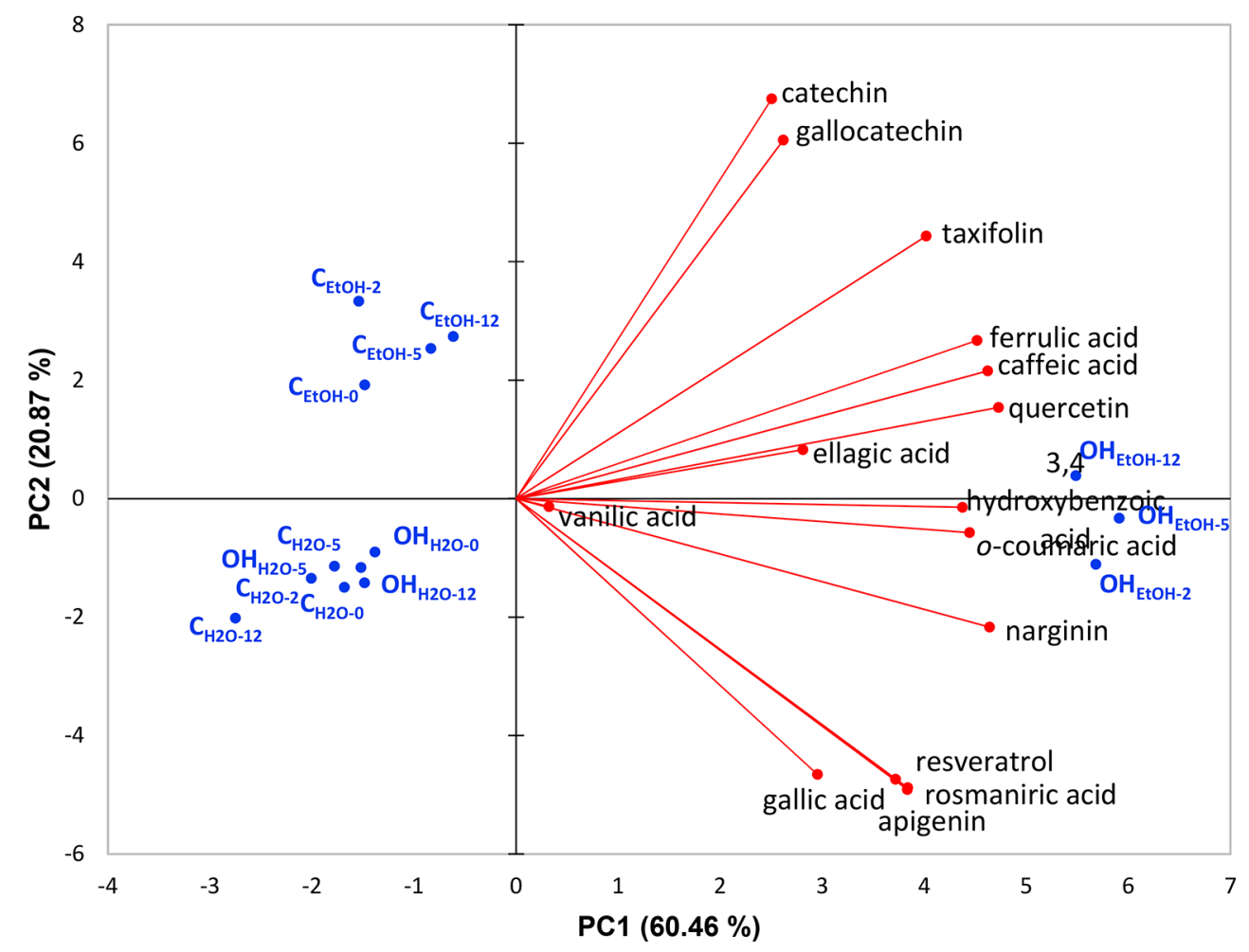

Figure 3. Principle component analysis (PCA) on the obtained extracts from Pinus pinaster bark. $\mathrm{C}_{\mathrm{EtOH}}-$ conventional heating with ethanol $50 \%$ $(\mathrm{v} / \mathrm{v})$ at different conductivities $0,2,5$, and $12 \mathrm{mS} / \mathrm{cm}$. $\mathrm{C}_{\mathrm{H} 2 \mathrm{O}}-$ conventional heating with water at different conductivities $0,2,5$, and $12 \mathrm{mS} / \mathrm{cm}$. $\mathrm{OH}_{\mathrm{EtOH}}-$ ohmic heating with ethanol $50 \%(\mathrm{v} / \mathrm{v})$ at different conductivities 2,5 , and $12 \mathrm{mS} / \mathrm{cm} . \mathrm{OH}_{\mathrm{H} 2 \mathrm{O}}-$ ohmic heating with water at different conductivities 2,5 , and $12 \mathrm{mS} / \mathrm{cm}$.

ABTS methods (up to $24 \%$ and $30 \%$, respectively). The increased activities in the hydroethanolic extracts measured with the different methods were as follows: up to $43 \%$ for $\mathrm{DPPH}$, up to $73 \%$ for FRAP, and up to $123 \%$ for ABTS. According to the results in the present work, significant correlations can be found between TPC and antioxidant activities of the obtained extracts. This is of a great importance for the industry, since the extracts of these byproducts are finding increasing applications as bioactive substances for example in food, chemical and pharmaceutical formulations.

This claim is supported by other researchers who previously demonstrated that extracts of the Pinus pinaster bark have a high antioxidant activity. $1,8,12,30,37$

Identification and Quantification of Phenolic Compounds. In total, 18 phenolic compounds were tested in the extracts of $P$. pinaster bark by UPLC (Table 3 ). The study of the individual phenolic compounds was meant to understand the action of the extraction technology and type of solvent over the chemical profile of the extracts. As far as we know there is little work done on the evaluation of extracts of $P$. pinaster by liquid chromatography. In this context the results presented here are also useful in terms of conventional extraction, bringing more information on the phenolic profile of extracts of $P$. pinaster.

In terms of the effect of the salt concentration (and, thus, the ionic strength and electrical conductivity) and as previously observed, there are no relevant differences in the concentration of phenolic compounds between extracts made by the same method and using the same solvent. The compounds with the highest concentrations in all samples were ellagic acid and taxifolin. Ellagic acid was found in concentrations between 179.6 and $402.2 \mathrm{mg} / \mathrm{L}$ that accounts for between $24.0 \%$ and $49.7 \%$ of the total phenolic compounds. Taxifolin was found in concentrations between 93.4 and $470.2 \mathrm{mg} / \mathrm{L}$, values that accounted for between $15.5 \%$ and $35.1 \%$ of the total phenolic compounds. Extracts from $P$. pinaster obtained with boiling water had $10.2 \mathrm{mg} / \mathrm{L}$ of catechin and $12.8 \mathrm{mg} / \mathrm{L}$ of taxifolin. ${ }^{38}$ These concentrations are three to ten times lower than the ones obtained in the present work for aqueous extracts.

Epicatechin and $p$-coumaric acid were identified in all samples. However, it was not possible to quantify these compounds, as they coeluted. Vanilic acid was only found in extracts made with conventional method and using hydroethanolic solution as solvent. The compounds apigenin, resveratrol, and rosmarinic acid were found only in extracts made with $50 \%$ ethanol. This can be explained by the nature of these phenols, once they are poorly soluble/extracted in water in normal conditions (such as pressure). In terms of the effect of moderate electric fields, extracts made with $\mathrm{OH}$ and hydroethanolic solvent had the highest total concentrations of phenolic compounds (between 1430.1 and $1565.1 \mathrm{mg} / \mathrm{L}$ ). This result is in accordance with the results obtained for the yields, TPC and antioxidant activities of the obtained extracts. Antioxidant activities of extracts increased in the way the total concentration of phenols increased. Extracts made with conventional and $\mathrm{OH}$ with water are similar in terms of concentration of individual phenol compounds, while extracts made with conventional and $\mathrm{OH}$ with $50 \%$ ethanol were different from the ones made with water, as well as different from each other. Some individual compounds (such as caffeic 


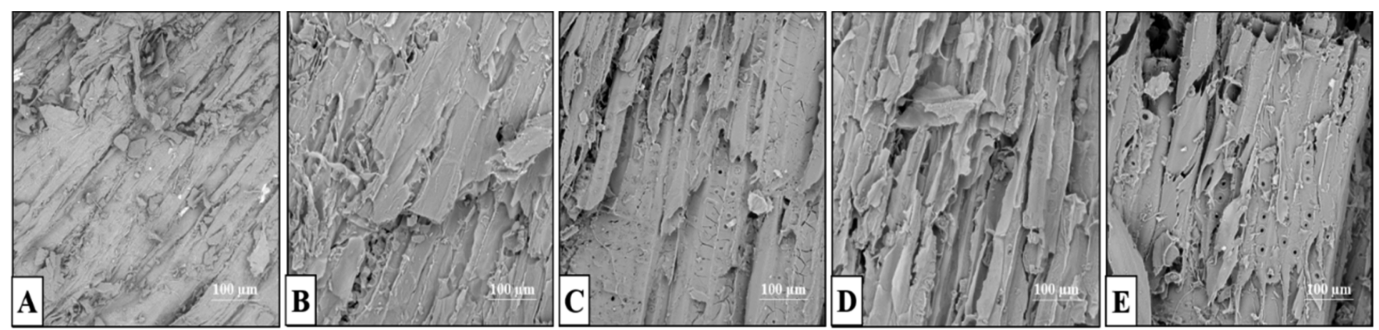

Figure 4. Micrographs by scanning electron microscopy of untreated (A), conventional heating (B and C), and ohmic heating (D and E) treatements of Pinus pinaster bark. B and D represent the bark after water extraction; C and E represent the bark after ethanol 50\% (v/v) extraction. The material analyzed comes from the residue subjected to extraction with a conductivity of $5 \mathrm{mS} / \mathrm{cm}$, except sample A.

acid, gallic acid, o-coumaric acid, ferrulic acid, narginin, apigenin, rosmarinic acid, taxifolin, and quercetin) had concentrations in the extracts made with $\mathrm{OH}$ and hydroethanolic solvent which were almost twice as higher as in the correspondent extracts obtained through conventional heating. This is well notorious for quercetin and taxifolin (dihydroquercetin). Both flavonoids have been described as good radical scavengers, and have demonstrated a wide range of benefits, such as anticarcinogenic, antioxidant, and antidiabetic activities, among many others, increasing the potential of application in food, chemical and pharmacological areas. ${ }^{9,39-43}$ Thus, the conditions and technologies studied in this work may be advantageous for the recovery and reuse of these types of molecules and may be interesting at the industrial level. Furthermore, the results also indicate that the process can be tuned for increased performance in terms of selective extraction of bioactive phenolic compounds.

PCA was performed on the phenolic compounds to visualize the differentiation of extracts on the basis of the type of solvent and the type of extraction methods used (Figure 3 ).

The first two principal components (PC1 and PC2) accounted for $81.33 \%$ of the total variance, $60.46 \%$ and $20.87 \%$, respectively. PCA analysis demonstrated good discrimination between samples. The PCA shows distribution of samples according to the type of solvent used for extraction, ethanol or water. All extracts made with water were similar $\left(\mathrm{C}_{\mathrm{H} 2 \mathrm{O}}\right.$ and $\left.\mathrm{OH}_{\mathrm{H} 2 \mathrm{O}}\right)$. Hydroethanolic extracts made with conventional method $\left(\mathrm{C}_{\mathrm{EtOH}}\right)$ and with $\mathrm{OH}\left(\mathrm{OH}_{\mathrm{EtOH}}\right)$ were distinguished between each other, as well as between the extracts made with water. Conventional extraction in hydroethanol is responsible for the variance in PC2 while $\mathrm{OH}$ extraction in ethanol for the variance in $\mathrm{PC} 2$. This may give an indication of a synergistic effect when $\mathrm{OH}$ and ethanol are combined in the extraction process. All phenolic compounds were distributed along at the positive loading of the PC1 and positive and negative loading of PC2. By the PCA distribution it is possible to conclude that $\mathrm{OH}$ with ethanol favors the extraction of compounds such as quercetin, narginin, and ellagic acid but in particular the acids 3,4 hydroxybenzoic and $o$-coumaric.

It also should be taken into consideration that distribution in positive and negative loading of $\mathrm{PC} 2$ can be related to the different levels of electrical conductivity and electric field intensity; for example, $\mathrm{OH}$ extraction in ethanol $50 \%(\mathrm{v} / \mathrm{v})$ of catechin seems to be favored at $12 \mathrm{mS} / \mathrm{cm}$, while gallic acid is better extracted at $2 \mathrm{mS} / \mathrm{cm}$. However, further studies will be necessary to evaluate electric field effects on the mechanism of extraction or even degradation of individual phenolic compounds.
SEM Analysis of Bark Morphology. The changes in the structure of the untreated, conventional heating and $\mathrm{OH}$ treated samples of $P$. pinaster bark were imaged by the scanning electron microscope (SEM; Figure 4).

The solvent and extraction method clearly influences the morphology of the pine bark cells. A visible appearance of pores in the cell walls can be observed in Figure 4C,E, which can facilitate extraction by contributing to an increase in the cell membrane's permeability, thus confirming the previous results (increase in extraction yield and quantity of total and individual phenols in extracts obtained by $50 \%$ ethanol). In addition, results also demonstrate that action of $\mathrm{OH}$ in hydroethanolic solution (Figure 4E) contributes to more significant changes in the morphological structure of the $P$. pinaster bark cells, also in accordance with the results described above. In this sense, together with thermal and solvent-driven morphological changes typical from solid-liquid solvent extraction, the eventual existence of an additional effect of electroporation should not be overlooked. Furthermore, different solvent behavior in the presence of $\mathrm{OH}$ indicates that the solvent's solvation and/or extraction properties are altered by the presence of an electric field and that this electricdriven effect is different from solvent to solvent.

The bark, leaves, and flowers are usually the plant parts richest in bioactive molecules and a rich source of phenolic compounds. These have several beneficial functions, such as protecting the plant from other agents (fungi, parasites, etc.) and promoting plant growth. Several studies have actually shown that bioactive compounds are present in the cellular skeleton of different species, located in different morphological parts of the tissues, both extracellular and intracellular. ${ }^{44,45}$ Moreover, many phenolic compounds are present inside the cell (in the lumens of vessels) and other parenchyma cells and fibers. ${ }^{44,46}$ In these cases, the extraction processes usually have to be more aggressive to cause rupture of the cell wall. Therefore, the use of temperature and organic solvents becomes necessary.

The results confirm what was expected. When $\mathrm{OH}$ is applied, an electroporation effect is expected to create pores in the membrane, helping extracting the compounds from the intracellular medium of the plant cells. ${ }^{11,18,47}$ In this case, the electrical effect can enhance the cellular permeabilization. In addition, comparing the $\mathrm{OH}$ methodology with other techniques available where high frequencies were applied (such as microwaves) for the extraction of intracellular bioactive compounds, the permeabilization of cells are described to be more effective in the case of $\mathrm{OH} .{ }^{10}$

Furthermore, the $\mathrm{OH}$ efficiency depends strongly on the dielectric constant of the solvent combination. In our case, the addition of water to the extraction medium leads to an increase 
in the polarity of the ethanol (or of the organic solvents in general), promoting a greater diffusion of the electric energy inside the sample, simultaneously provoking an increase in temperature. The combination of these factors (electrical and thermal) leads to cellular permeabilization and an easier release of phenolic compounds. ${ }^{29,33}$ The application of electric fields in the extraction process of vegetal material usually promotes an increase in the permeability of the cellular wall. This phenomenon occurs because the cell membrane had a specific dielectric strength that has been exceeded by the electric field exerted by the ohmic heating process, causing an increase in the electroporation mechanism. ${ }^{22,28,33}$ The electric energy applied between the electrodes in $\mathrm{OH}$ was responsible for the breakdown of the pine bark cell membranes, which enabled the extraction in a much easier way when compared to the conventional extraction. Despite these promising results, more fundamental studies will be necessary to confirm extraction pathways in this kind of material under $\mathrm{OH}$ conditions, which can combine enhanced thermal permeabilization but also electroporation effects, or even combination of both.

Determination of Energy Consumption. Figure 5 shows total energy consumption of conventional and $\mathrm{OH}$ -

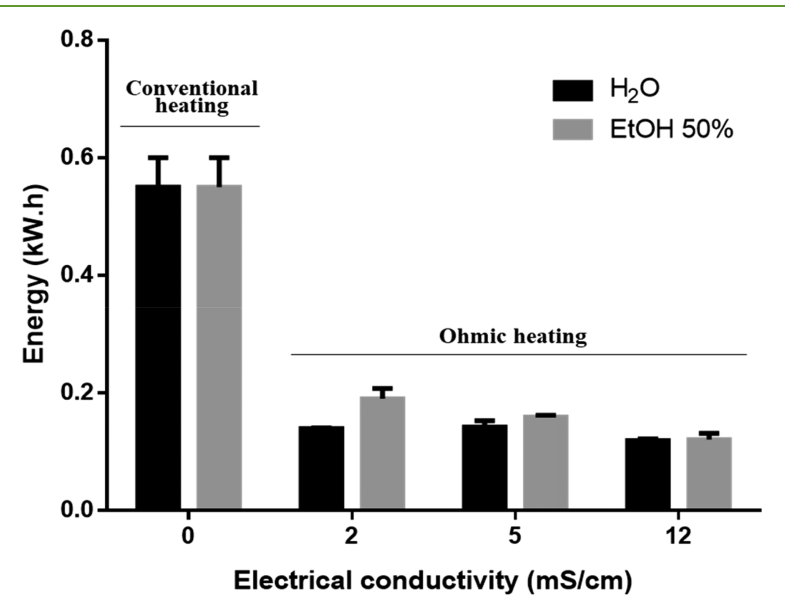

Figure 5. Total energy consumption of conventional heating and $\mathrm{OH}-$ assisted extraction methods for water and hydroethanolic (EtOH $50 \%$ ) extraction at different electrical conductivities. Values are expressed as mean $\pm \mathrm{SD}$ of three experiments.

assisted extraction for the two solvents applied in this work. For this study, the electric field strength applied to maintain the temperature of $83{ }^{\circ} \mathrm{C}$ during the extraction process was 0 $\mathrm{V} / \mathrm{cm}$ in the case of conventional heating, and 5,10 , and $15 \mathrm{~V} /$ $\mathrm{cm}$ for conductivities of 12,5 , and $2 \mathrm{mS} / \mathrm{cm}$, respectively, when applying $\mathrm{OH}$ technology. In the case of conventional thermal extraction, the conductivity did not affect the energy consumption, and for calculating the energy supplied during the process, the time and intensity at which the heating source was operated (which was the same for both solvents) was taken into account. As expected, conventional heating resulted in the highest energy consumption (approximately 0.5 kW.h). Despite $\mathrm{OH}$ being a thermal process, levels of energy input were significantly lower $(P<0.001)$ when compared with conventional heating for both solvents using the same thermal profile (i.e., heating rate, temperature, and treatment time). In the case of hydroethanolic extraction the energy consumption of $\mathrm{OH}$ decreased with increasing electrical conductivity of extraction medium (and respective decrease of the electric field applied).

At lab scale, the conventional extraction step in the recovery of compounds from natural products may account for $90 \%$ of the overall energy spending. ${ }^{17}$ In this context, and given the dependence on fossil-based nonrenewable energy sources, the relation between energy consumption and $\mathrm{CO}_{2}$ emissions and the high energy price, the reduction of ca. $70 \%$ in energy consumption associated with the use of $\mathrm{OH}$ will definitely have an important impact on the environmental performance of the extraction process.

In comparison with alternative technologies, the results with $\mathrm{OH}$ are also encouraging. For instance, the microwave heating technology has been often described as a green extraction alternative to conventional extraction but showed relatively low energetic efficiency in comparison to $\mathrm{OH}$ (this study). Whereas the magnetron source of microwave is typically $67 \%$ efficient, if one includes transmission losses, the efficiency becomes closer to $50 \%$. By contrast, $\mathrm{OH}$ is over $90 \%$ efficient. $^{12,48}$

At an industrial scale, the conventional thermal extraction process uses more energy efficient methodologies, not having as sharp expenditures as those observed in laboratory scale. Nevertheless, $\mathrm{OH}$ technology is a process with the potential to reduce energy consumption and associated costs even at a larger scale, thus, less environment impact. ${ }^{48}$

\section{CONCLUSIONS}

$\mathrm{OH}$-assisted extraction caused a significant increase in total phenolic compounds concentration in Pinus pinaster bark extracts (ranging from 17 to $100 \%$ increase in comparison with conventional heating) with significant saves in energy consumption. The use of ethanol in combination with $\mathrm{OH}$ altered the process selectivity, further boosting the extraction yield of phenolic compounds and increasing the antioxidant activities. A more comprehensive understanding about the influence of $\mathrm{OH}$ electrical variables (such as electric field intensity, electrical frequency, type of waveform, or even current density) on the morphological structure of the $P$. pinaster bark cells, solvents properties and extracts profile may bring new insights on development of extraction protocols aiming at selective extraction. Even so, the increased extraction yield leads to a more efficient extraction process with lower waste generation. Furthermore, as the process seems to cause significant cell permeabilization, it is expected that the solvent access to the compounds to extract will be facilitated, allowing the use of lower amounts of solvent to reach the same productivity.

In short, $\mathrm{OH}$ technology holds the potential to be a "green" technique for the extraction of bioactive compounds, namely phenolic compounds from pine bark, with significant improvements in yields and phenolic content and reduced energy consumption. Furthermore, the results also indicate that the process can be tuned for increased performance in terms of selective extraction of bioactive phenolic compounds.

\section{AUTHOR INFORMATION}

\section{Corresponding Author}

*E-mail: cmrochainv@gmail.com. Telephone: +351 253604400 .

ORCID $\odot$

Pedro Ferreira-Santos: 0000-0002-9427-4605 
Zlatina Genisheva: 0000-0002-9367-1385

Ricardo N. Pereira: 0000-0003-1553-9693

José A. Teixeira: 0000-0002-4918-3704

Cristina M. R. Rocha: 0000-0003-4687-0266

Notes

The authors declare no competing financial interest.

\section{ACKNOWLEDGMENTS}

This work was supported by the Portuguese Foundation for Science and Technology - FCT (under the scope of the strategic funding of UID/BIO/04469/2019 unit and project 029145), COMPETE 2020 (POCI-01-0145-FEDER-029145), BioTecNorte operation (NORTE-01-0145-FEDER-000004, funded by the European Regional Development Fund under the scope of Norte2020 - Programa Operacional Regional do Norte), and by program INTERREG V-B Sudoe (REDVALUE, SOE1/P1/E0123). P.S. is the recipient of a fellowship supported by a doctoral advanced training (NORTE-08-5369FSE-000036, call NORTE-69-2015-15), funded by the European Social Fund under the scope of Norte2020 - Programa Operacional Regional do Norte. Z.G. is the recipient of a fellowship supported by FCT (SFRH/BPD/108868/2015).

\section{REFERENCES}

(1) Seabra, I. J.; Dias, A. M. A.; Braga, M. E. M.; de Sousa, H. C. High pressure solvent extraction of maritime pine bark: Study of fractionation, solvent flow rate and solvent composition. J. Supercrit. Fluids 2012, 62, 135-148.

(2) ICNF. IFN6 - Áreas dos usos do solo e das espécies florestais de Portugal continental [pdf]. Instituto da Conservação da Natureza e das Florestas; Lisboa, 2013; www2.icnf.pt/portal/florestas/ifn.

(3) Miranda, I.; Gominho, J.; Mirra, I.; Pereira, H. Chemical characterization of barks from Picea abies and Pinus sylvestris after fractioning into different particle sizes. Ind. Crops Prod. 2012, 36 (1), $395-400$.

(4) Fradinho, D. M.; Neto, C. P.; Evtuguin, D.; Jorge, F. C.; Irle, M. A.; Gil, M. H.; Pedrosa de Jesus, J. Chemical characterisation of bark and of alkaline bark extracts from maritime pine grown in Portugal. Ind. Crops Prod. 2002, 16 (1), 23-32.

(5) Rohdewald, P. A review of the French maritime pine bark extract (Pycnogenol), a herbal medication with a diverse clinical pharmacology. Int. J. Clin. Pharmacol. Ther. 2002, 40 (4), 158-168.

(6) Jerez, M.; Touriño, S.; Sineiro, J.; Torres, J. L.; Núñez, M. J. Procyanidins from pine bark: Relationships between structure, composition and antiradical activity. Food Chem. 2007, 104 (2), $518-527$.

(7) Jerez, M.; Selga, A.; Sineiro, J.; Torres, J. L.; Núñez, M. J. A comparison between bark extracts from Pinus pinaster and Pinus radiata: Antioxidant activity and procyanidin composition. Food Chem. 2007, 100 (2), 439-444.

(8) Maimoona, A.; Naeem, I.; Saddiqe, Z.; Jameel, K. A review on biological, nutraceutical and clinical aspects of French maritime pine bark extract. J. Ethnopharmacol. 2011, 133 (2), 261-277.

(9) Iravani, S.; Zolfaghari, B. Pharmaceutical and nutraceutical effects of Pinus pinaster bark extract. Res. Pharm. Sci. 2011, 6 (1), 111.

(10) Aspé, E.; Fernández, K. The effect of different extraction techniques on extraction yield, total phenolic, and anti-radical capacity of extracts from Pinus radiata Bark. Ind. Crops Prod. 2011, 34 (1), 838-844.

(11) Rocha, C. M. R.; Genisheva, Z.; Ferreira-Santos, P.; Rodrigues, R.; Vicente, A. A.; Teixeira, J. A.; Pereira, R. N. Electric field-based technologies for valorization of bioresources. Bioresour. Technol. 2018, $254,325-339$.

(12) Mellouk, H.; Meullemiestre, A.; Maache-Rezzoug, Z.; Bejjani, B.; Dani, A.; Rezzoug, S.-A. Valorization of industrial wastes from
French maritime pine bark by solvent free microwave extraction of volatiles. J. Cleaner Prod. 2016, 112, 4398-4405.

(13) Ghitescu, R.-E.; Volf, I.; Carausu, C.; Bühlmann, A.-M.; Gilca, A.; Popa, V. I. Optimization of ultrasound-assisted extraction of polyphenols from spruce wood bark. Ultrason. Sonochem. 2015, 22, 535-541.

(14) Arshadi, M.; Attard, T. M.; Lukasik, R. M.; Brncic, M.; da Costa Lopes, A. M.; Finell, M.; Geladi, P.; Gerschenson, L. N.; Gogus, F.; Herrero, M.; Hunt, A. J.; Ibáñez, E.; Kamm, B.; Mateos-Aparicio, I.; Matias, A.; Mavroudis, N. E.; Montoneri, E.; Morais, A. R. C.; Nilsson, C.; Papaioannou, E. H.; Richel, A.; Rupérez, P.; Škrbić, B.; BodrožaSolarov, M.; Švarc-Gajić, J.; Waldron, K. W.; Yuste-Córdoba, F. J. Pre-treatment and extraction techniques for recovery of added value compounds from wastes throughout the agri-food chain. Green Chem. 2016, 18 (23), 6160-6204.

(15) Cvjetko Bubalo, M.; Vidović, S.; Radojčíc Redovniković, I.; Jokić, S. New perspective in extraction of plant biologically active compounds by green solvents. Food Bioprod. Process. 2018, 109, 5273.

(16) Herrero, M.; Ibañez, E. Green extraction processes, biorefineries and sustainability: Recovery of high added-value products from natural sources. J. Supercrit. Fluids 2018, 134, 252-259.

(17) Chemat, F.; Fabiano-Tixier, A. S.; Abert, M.; Allaf, T.; Vorobiev, E. Trends in Analytical Chemistry Solvent-free extraction of food and natural products. TrAC, Trends Anal. Chem. 2015, 71, 157168.

(18) Pereira, R. N.; Rodrigues, R. M.; Genisheva, Z.; et al. Effects of ohmic heating on extraction of food-grade phytochemicals from colored potato. LWT - Food Sci. Technol. 2016, 74, 493-503.

(19) Loypimai, P.; Moongngarm, A.; Chottanom, P.; Moontree, T. Ohmic heating-assisted extraction of anthocyanins from black rice bran to prepare a natural food colourant. Innovative Food Sci. Emerging Technol. 2015, 27, 102-110.

(20) Aamir, M.; Jittanit, W. Ohmic heating treatment for Gac aril oil extraction: Effects on extraction efficiency, physical properties and some bioactive compounds. Innovative Food Sci. Emerging Technol. 2017, 41, 224-234.

(21) Pereira, R. N.; Souza, B. W. S.; Cerqueira, M. A.; Teixeira, J. A.; Vicente, A. A. Effects of Electric Fields on Protein Unfolding and Aggregation: Influence on Edible Films Formation. Biomacromolecules 2010, 11 (11), 2912-2918.

(22) Nair, G. R.; Divya, V. R.; Prasannan, L.; Habeeba, V.; Prince, M. V.; Raghavan, G. S. V. Ohmic heating as a pre-treatment in solvent extraction of rice bran. J. Food Sci. Technol. 2014, 51 (10), 26922698.

(23) Sluiter, A.; Ruiz, A.; Scarlata, C.; Sluiter, J.; Templeton, D. Determination of Extractives in Biomass: Laboratory Analytical Procedure (LAP), Issue Date 7/17/2005; U.S. National Renewable Energy Laboratory, 2008, Technical Report NREL/TP-510-42621.

(24) Singleton, V. L.; Orthofer, R.; Lamuela-Raventós, R. M. Analysis of total phenols and other oxidation substrates and antioxidants by means of folin-ciocalteu reagent. Methods Enzymol. 1999, 299, 152-178.

(25) Ballesteros, L. F.; Cerqueira, M. A.; Teixeira, J. A.; Mussatto, S. I. Characterization of polysaccharides extracted from spent coffee grounds by alkali pretreatment. Carbohydr. Polym. 2015, 127, 347354.

(26) Benzie, I. F. F.; Strain, J. J. The Ferric Reducing Ability of Plasma (FRAP) as a Measure of "Antioxidant Power": The FRAP Assay. Anal. Biochem. 1996, 239 (1), 70-76.

(27) Meneses, N. G. T.; Martins, S.; Teixeira, J. A.; Mussatto, S. I. Influence of extraction solvents on the recovery of antioxidant phenolic compounds from brewer's spent grains. Sep. Purif. Technol. 2013, 108, 152-158.

(28) Vorobiev, E.; Lebovka, N. Enhanced Extraction from Solid Foods and Biosuspensions by Pulsed Electrical Energy. Food Eng. Rev. 2010, 2 (2), 95-108. 
(29) Bouras, M.; Grimi, N.; Bals, O.; Vorobiev, E. Impact of pulsed electric fields on polyphenols extraction from Norway spruce bark. Ind. Crops Prod. 2016, 80, 50-58.

(30) Chupin, L.; Maunu, S. L.; Reynaud, S.; Pizzi, A.; Charrier, B.; Charrier-EL Bouhtoury, F. Microwave assisted extraction of maritime pine (Pinus pinaster) bark: Impact of particle size and characterization. Ind. Crops Prod. 2015, 65, 142-149.

(31) Moreira, M. M.; Barroso, M. F.; Boeykens, A.; Withouck, H.; Morais, S.; Delerue-Matos, C. Valorization of apple tree wood residues by polyphenols extraction: Comparison between conventional and microwave-assisted extraction. Ind. Crops Prod. 2017, 104, 210-220.

(32) Bouras, M.; Chadni, M.; Barba, F. J.; Grimi, N.; Bals, O.; Vorobiev, E. Optimization of microwave-assisted extraction of polyphenols from Quercus bark. Ind. Crops Prod. 2015, 77, 590-601.

(33) Lebovka, N. I.; Praporscic, I.; Ghnimi, S.; Vorobiev, E. Does Electroporation Occur During the Ohmic Heating of Food? J. Food Sci. 2005, 70 (5), E308-E311.

(34) Hoon, Y. L.; Choo, C.; Watawana, M. I.; Jayawardena, N.; Waisundara, V. Y. Short communications, Evaluation of the total antioxidant capacity and antioxidant compounds of different solvent extracts of Chilgoza pine nuts (Pinus gerardiana). J. Funct. Foods 2015, 18, 1014-1021.

(35) Barros, L.; Oliveira, S.; Carvalho, A. M.; Ferreira, I.C. F. R. In vitro antioxidant properties and characterization in nutrients and phytochemicals of six medicinal plants from the Portuguese folk medicine. Ind. Crops Prod. 2010, 32 (3), 572-579.

(36) Alam, M. N.; Bristi, N. J.; Rafiquzzaman, M. Review on in vivo and in vitro methods evaluation of antioxidant activity. Saudi Pharm. J. 2013, 21 (2), 143-152.

(37) Braga, M. E. M.; Santos, R. M. S.; Seabra, I. J.; Facanali, R.; Marques, M. O. M.; de Sousa, H. C. Fractioned SFE of antioxidants from maritime pine bark. J. Supercrit. Fluids 2008, 47 (1), 37-48.

(38) Gascón, S.; Jiménez-Moreno, N.; Jiménez, S.; Quero, J.; Rodríguez-Yoldi, M. J.; Ancín-Azpilicueta, C. Nutraceutical composition of three pine bark extracts and their antiproliferative effect on Caco-2 cells. J. Funct. Foods 2018, 48, 420-429.

(39) Guo, H.; Zhang, X.; Cui, Y.; Zhou, H.; Xu, D.; Shan, T.; Zhang, F.; Guo, Y.; Chen, Y.; Wu, D. Taxifolin protects against cardiac hypertrophy and fibrosis during biomechanical stress of pressure overload. Toxicol. Appl. Pharmacol. 2015, 287 (2), 168-177.

(40) Akinmoladun, A. C.; Oladejo, C. O.; Josiah, S. S.; Famusiwa, C. D.; Ojo, O. B.; Olaleye, M. T. Catechin, quercetin and taxifolin improve redox and biochemical imbalances in rotenone-induced hepatocellular dysfunction: Relevance for therapy in pesticide-induced liver toxicity? Pathophysiology 2018, 25 (4), 365-371.

(41) Sun, X.; Chen, R. C.; Yang, Z. H.; Sun, G. B.; Wang, M.; Ma, X. J.; Yang, L. J.; Sun, X. B. Taxifolin prevents diabetic cardiomyopathy in vivo and in vitro by inhibition of oxidative stress and cell apoptosis. Food Chem. Toxicol. 2014, 63, 221-232.

(42) Baranowska, M.; Suliborska, K.; Chrzanowski, W.; Kusznierewicz, B.; Namieśnik, J.; Bartoszek, A. The relationship between standard reduction potentials of catechins and biological activities involved in redox control. Redox Biol. 2018, 17, 355-366.

(43) Patil, V. M.; Masand, N. Anticancer Potential of Flavonoids: Chemistry, Biological Activities, and Future Perspectives. In Studies in Natural Products Chemistry; Elsevier: Amsterdam, 2019; Vol. 59, pp 401-430 DOI: 10.1016/B978-0-444-64179-3.00012-8.

(44) Koch, G.; Schmitt, U. Topochemical and Electron Microscopic Analyses on the Lignification of Individual Cell Wall Layers During Wood Formation and Secondary Changes. In Cellular Aspects of Wood Formation, Plant Cell Monographs; Fromm, J., Eds.; Springer Press: Berlin, 2013, DOI: 10.1007/978-3-642-36491-4 2.

(45) Koch, G.; Kleist, G. Application of Scanning UV Microspectrophotometry to Localise Lignins and Phenolic Extractives in Plant Cell Walls. Holzforschung 2001, 55 (6), 091 DOI: 10.1515/ HF.2001.091.

(46) Li, S.-H.; Nagy, N. E.; Hammerbacher, A.; Krokene, P.; Niu, X.M.; Gershenzon, J.; Schneider, B. Localization of Phenolics in Phloem
Parenchyma Cells of Norway Spruce (Picea abies). ChemBioChem 2012, 13 (18), 2707-2713.

(47) El Darra, N.; Grimi, N.; Vorobiev, E.; Louka, N.; Maroun, R. Extraction of Polyphenols from Red Grape Pomace Assisted by Pulsed Ohmic Heating. Food Bioprocess Technol. 2013, 6 (5), 12811289.

(48) Pereira, R. N.; Vicente, A. A. Environmental impact of novel thermal and non-thermal technologies in food processing. Food Res. Int. 2010, 43 (7), 1936-1943. 